\title{
Is it time for some new ideas for patients undergoing the Fontan operation? Here is some food for thought
}

\author{
Osman O. Al-Radi, MBBCh, MSc, FRCSC
}

\footnotetext{
From the Department of Surgery, Abdullah Bakhsh Children's Heart Center, Faculty of Medicine, King Abdulaziz University, Jeddah, Saudi Arabia.

Disclosures: Author has nothing to disclose with regard to commercial support.

Received for publication Feb 26, 2017; accepted for publication March 31, 2017; available ahead of print April 25, 2017.

Address for reprints. Osman O. Al-Radi, MBBCh, MSc, FRCSC, Department of Surgery, Abdullah Bakhsh Children's Heart Center, Faculty of Medicine, King Abdulaziz University, PO Box 80215, Building 10, Room 1027, Jeddah 21589, Saudi Arabia (E-mail: oradi@kau.edu.sa).

J Thorac Cardiovasc Surg 2017;154:254-5

$0022-5223 / \$ 36.00$

Copyright (c 2017 by The American Association for Thoracic Surgery

http://dx.doi.org/10.1016/j.jtcvs.2017.03.136
}

Children born with hypoplastic left heart syndrome and other forms of single-ventricle anomalies were once left to die in dark corners of pediatric wards of the leading children's hospitals all over the world. ${ }^{1,2}$ This was true in the developed world until the mid 1980's and is still true in much of the developing world. It was the audacity of making and accepting change exhibited by a small group of pioneer surgeons and pediatric cardiologists that led to the revolution we see today in the care of children with single-ventricle anomalies.

In the current era, operative mortality for stage-one single-ventricle palliation, most commonly a Norwood-type operation, hovers around a stubborn $15 \%$. ${ }^{4}$ The less welldocumented interstage mortality is also still significant. Mortality for the subsequent stages is much lower; however, it has not been eliminated. ${ }^{4}$ It is not hard to argue that the current outcomes can, and should, be improved further. It is also not hard to argue that best targets for change should address the early stages of care and better preparation of these patients - starting from birth and perhaps before-for the final palliation stage, namely the Fontan operation.

In the current issue of the Journal, Downing and colleagues ${ }^{5}$ report one of the most comprehensive and complete follow-up studies of patients undergoing the Fontan operation in the current era. The cohort was very consistent in the type of operation received. All patients underwent a total cavopulmonary connection, either lateral tunnel or extracardiac conduit. Failure was defined as death, heart transplant, or Fontan takedown. Because of their well-structured statistical analysis of these 773 patients with $99.2 \%$ complete follow-up, Downing and colleagues ${ }^{5}$ could identify 2 distinct sets of predictors of failure. Early failure, within 1 year of the Fontan operation, was predicted by prolonged (>14 days) pleural drainage (hazard ratio [HR], 4.4), prolonged ( $>7$ days) intensive care unit stay (HR, 2.4), Fontan operation before 1997 (HR, 3.3), preoperative atrioventricular valve regurgitation of at least mild degree (HR, 2), and

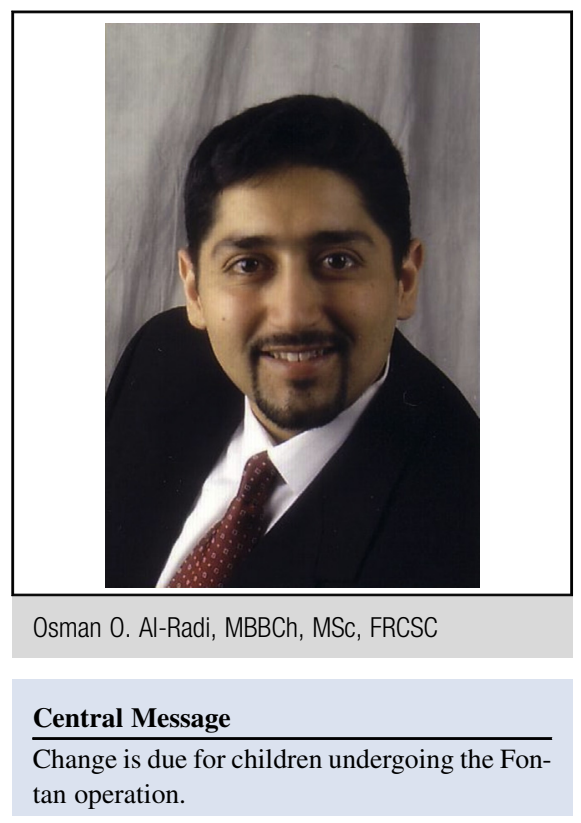

See Article page 243 longer crossclamp time (HR, 1.3 for every 10 minutes of extra clamp time). On the other hand, late failure, beyond 1 year of follow-up, was predicted by preoperative atrioventricular valve regurgitation ( $\mathrm{HR}, 2)$ and prolonged ( $>7$ days) intensive care unit stay (HR, 2.4). A subset of patients $(n=627)$ underwent a preoperative catheterization, and their mean pulmonary arterial pressures were available. In this subanalysis, the strongest predictor of early failure was mean pulmonary arterial pressure greater than $15 \mathrm{~mm}$ $\mathrm{Hg}$ (HR, 4.1). The other factors remained significant predictors.

On the basis of these findings, one might suggest that the next steps in changing what we do for this group of patients might be any or all of the following ideas, and surely many more: (1) Improve the selection of patients who undergo a Fontan operation by strict adherence to a maximum mean pulmonary arterial pressure of $15 \mathrm{~mm} \mathrm{Hg}$. (2) Repair any mild or greater degree of atrioventricular valve regurgitation before the Fontan stage, at the superior cavopulmonary anastomosis stage, or as a separate operation. (3) Perform early conversion from a parallel circulation to a Glenn circulation to shorten the interstage time and to reduce volume overload. (4) Take measures to reduce collateral circulation surgically or by catheter intervention. 
Another form of change due might be one of labeling. Currently, the label "failing Fontan circulation" is given to a patient who either acutely or chronically exhibits the complications of a high-pressure Fontan circulation, such as ascites and protein-losing enteropathy. I argue that this label should be changed to the "failed Fontan circulation." The "failing Fontan circulation" label suggests predicting failure before it happens or failure in its early stages, and this should be given to patients who exhibit earlier signs of trouble. According to Downing and colleagues, ${ }^{5}$ a patient who stayed longer than a week in the intensive care unit after a Fontan operation has a risk of long-term failure (death, transplant, or Fontan takedown) of $35 \%$. If this patient also had mild or greater atrioventricular valve regurgitation, the risk of failure doubles to about $70 \%$. In my opinion, such a patient is deserving of the label "failing Fontan circulation" even before the development of complications attributable to a "failed Fontan circulation." This change in labeling, followed by a change in clinical behavior, might put these patients on a track that can avoid failure, namely earlier heart transplant. Some might argue that this is impossible or impractical because of the major challenges of donor heart allocation and the already burdened system with limited donors. Here is some more food for thought, however, in this era of long-term assist devices lasting for many years with very good results. I would like to pose a question, should donor hearts be allocated to children and young adults with failing repaired congenital heart disease who have many more potential years of life compared in preference to adults who might be able to achieve similar life expectancy with a long-tern assist device as they would with a heart transplant?

In the title, I wrote that this was food for thought. I didn't say it was easy to digest!

\section{References}

1. Zahka KG, Spector M, Hanisch D. Hypoplastic left-heart syndrome Norwood operation, transplantation, or compassionate care. Clin Perinatol. 1993;20:145-54.

2. Prsa M, Holly CD, Carnevale FA, Justino H, Rohlicek CV. Attitudes and practices of cardiologists and surgeons who manage HLHS. Pediatrics. 2010;125:e625-30.

3. Norwood WI, Kirklin JK, Sanders SP. Hypoplastic left heart syndrome: experience with palliative surgery. Am J Cardiol. 1980;45:87-91.

4. Jacobs JP, Mayer JE Jr, Mavroudis C, O’Brien SM, Austin EH 3rd, Pasquali SK, et al. The Society of Thoracic Surgeons Congenital Heart Surgery Database: 2017 update on outcomes and quality. Ann Thorac Surg. 2017;103:699-709.

5. Downing TE, Allen KY, Glatz AC, Rogers LS, Ravishankar C, Rychik J, et al. Long-term survival after the Fontan operation: twenty years of experience at a single center. J Thorac Cardiovasc Surg. 2017;154:243-53.e2. 